\title{
PENINGKATAN PERAN KELOMPOK SWADAYA MASYARAKAT TERHADAP MEDIA PROMOSI DI DESA WISATA DUSUN MENDIRO
}

\author{
Edy Widodo ${ }^{1}$, Sekti Kartika Dini ${ }^{1 *}$, Achmad Fauzan ${ }^{1}$, Novendri Isra Asriny ${ }^{1}$, Muthia Citra \\ Safira ${ }^{1}$
}

\author{
Program Studi Statistika, Fakultas Matematika dan Ilmu Pengetahuan Alam, Universitas Islam Indonesia, \\ Yogyakarta, Indonesia \\ *Penulis Korespodensi : sektidini@uii.ac.id
}

\begin{abstract}
Abstrak
Sektor pariwisata merupakan salah satu potensi dari kekayaan Indonesia yang menjadi sumber pemasukan devisa negara. Desa wisata menjadi salah satu tren pengembangan pariwisata di Indonesia. Daerah Istimewa Yogyakarta merupakan destinasi wisata paling popular di Indonesia setelah Bali. Dusun Mendiro terletak di Kelurahan Sukoharjo Kecamatan Ngaglik Kabupaten Sleman Yogyakarta memiliki kebudayaan lokal yang khas dan masih terjaga serta berpotensi untuk dijadikan sebagai desa wisata alternatif. Begitu banyak potensi yang dimiliki oleh kawasan desa wisata tersebut, namun masih terdapat beberapa hal yang belum dipotimalkan khusunya dalam bidang promosi. Oleh karena itu perlu dilaksanakan pengabdian masyarakat dengan target Kelompok Swadaya Masyarakat (KSM) Dusun Mendiro yang bertujuan optimalisasi kemampuan sumberdaya dalam manajemen media promosi desa wisata. Metode pengabdian ini dilaksanakan dalam bentuk pembelajaran dan pendampingan masyarakat yang secara detail dibagi menjadi tiga tahapan, yakni: (1) persiapan, (2) pelaksanaan, (3) evaluasi dan rencana keberlanjutan program. Berdasarkan hasil evaluasi diperoleh informasi adanya peningkatan pemahaman peserta pengabdian masyarakat terkait penyuluhan Google Form sebesar 21.01\% dan peningkatan sebesar $58.7 \%$ untuk penyuluhan media permainan Kahoot. Selain itu, diketahui bahwa secara keseluruhan peserta menyatakan bahwa adanya pelatihan yang diberikan oleh tim bermanfaat yang dapat digunakan oleh peserta untuk mengelola desa wisata dan perlu diadakan kembali.
\end{abstract}

Kata kunci: Desa Wisata; Google Form; Kahoot; Kelompok Swadaya Masyarakat.

\begin{abstract}
The tourism sector is one of the potential wealth of Indonesia, which is a source of foreign exchange income for the country. Village tourism is one of the tourism developments trends in Indonesia. Daerah Istimewa Yogyakarta is the most popular tourist destination in Indonesia after Bali. Mendiro is located in Sukoharjo Village, Ngaglik District, Sleman Regency, Yogyakarta, which has a distinctive local culture and is still maintained and has the potential to be used as an alternative tourism village. The tourist village area owns so much potential, but there are still some things that have not been optimized especially in the field of promotion. Therefore, it is necessary to carry out community service targeting the Mendiro Community Groups (KSM) aimed at optimizing the ability of resources in the management of media promotion of tourism villages. This service method is implemented in the form of learning and community facilitation, which is divided into three stages, namely: (1) preparation, (2) implementation, (3) evaluation and plan for program sustainability. Based on the evaluation results obtained information that there is an increase in understanding of community service participants related to Google Form extension by $21.01 \%$ and an increase of $58.7 \%$ for Kahoot game media extension. Besides, it was known that overall the participants stated that there was training provided by a useful team which could be used by participants to manage the tourism village and needed to be held again.
\end{abstract}

Keywords: The Village Tourism; Google Form; Kahoot; The Community Groups.

\section{PENDAHULUAN}

Sektor pariwisata merupakan salah satu potensi dari kekayaan Indonesia yang menjadi sumber pemasukan devisa negara. Selain itu, Indonesia adalah negara yang mempunyai beragam jenis pariwisata, yakni wisata alam, sosial, dan budaya. Mengacu dari definisi asalnya, pariwisata adalah keseluruhan rangkaian kegiatan yang berkaitan dengan gerakan manusia melalui kegiatan perjalanan atau persinggahan sementara dari tempat tinggalnya, ke suatu atau di beberapa tempat tujuan yang dipengaruhi oleh beberapa keperluan tanpa bermaksud mencari nafkah (Gunn, 2002). 
Salah satu pendekatan pengembangan wisata alternatif adalah melalui desa wisata untuk pembangunan pedesaan yang berkelanjutan dalam bidang pariwisata (Yoeti, 1996). Belakangan ini, desa wisata sudah menjadi salah satu tren pengembangan pariwisata di Indonesia, dimana tren ini menjawab dari arah baru dalam berwisata (Puta, 2018). Desa wisata merupakan kawasan pedesaan yang mempunyai beberapa karakteristik khusus untuk menjadi daerah tujuan wisata. Penduduk di kawasan desa wisata memiliki budaya dan tradisi yang masih asli, dilengkapi faktor pendukung seperti makanan khas, sistem pertanian, kondisi lingkungan, dan sistem sosial turut mewarnai sebuah desa wisata.

Daerah Istimewa Yogyakarta merupakan destinasi wisata paling popular di Indonesia setelah Bali. Objek wisata yang ditawarkan oleh daerah istimewa ini beragam. Selain itu, warga Yogyakarta juga dikenal sebagai penduduk yang ramah sehingga membuat wisatawan yang berkunjung merasa nyaman dan ingin kembali mengunjungi provinsi ini.
Dusun Mendiro terletak di Kelurahan Sukoharjo Kecamatan Ngaglik Kabupaten Sleman Yogyakarta. Dusun ini memiliki kondisi alam dan lingkungan yang masih asri. Di sisi lain, Dusun Mendiro memiliki kebudayaan lokal yang khas dan masih terjaga serta berpotensi untuk dijadikan sebagai desa wisata alternatif. Dusun ini mempunyai nama khas yakni Dewa Sikuba Mendiro yang merupakan singkatan dari Desa Wisata Edukasi Lingkungan dan Budaya Mendiro.

Begitu banyak potensi yang dimiliki oleh kawasan desa wisata tersebut, namun masih terdapat beberapa hal yang belum dipotimalkan khusunya dalam bidang promosi, baik secara online (website maupun sosial media) serta offline (surat kabar, kerjasama, maupun penyebaran informasi secara massal). Kegiatan promosi merupakan salah satu strategi penting untuk menyebarluaskan suatu produk atau jasa agar dapat dikenal. Sebaik atau seindah apapun produk jika kurang dari sisi promosi lama kelamaan akan turun terlebih untuk produk wisata yang belum begitu dikenal masyarakat umum. Kondisi umum Dusun Mendiro disajikan pada Gambar 1.

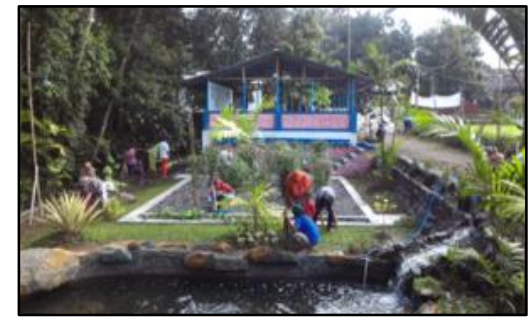

a. IPAL Komunal

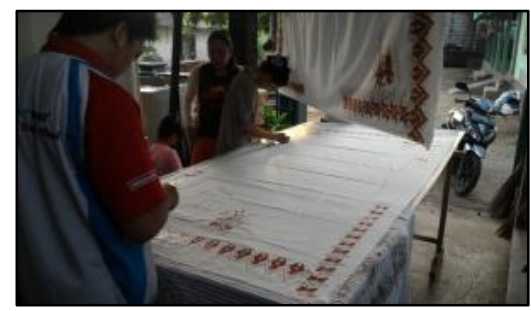

d. Kerajinan batik

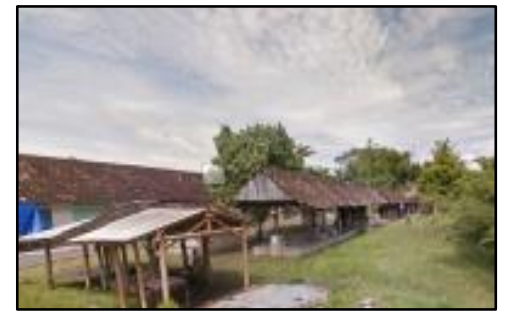

b. Pasar Setom

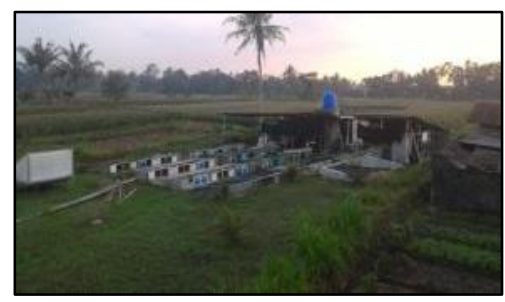

e. Budidaya gangga spirulina

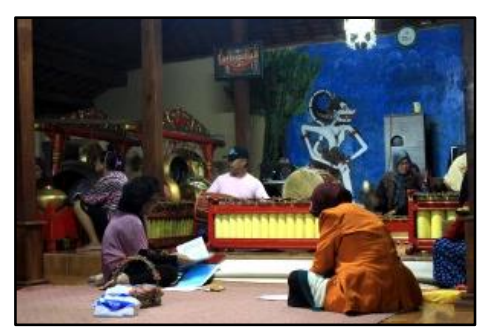

c. Joglo Sutodiryan

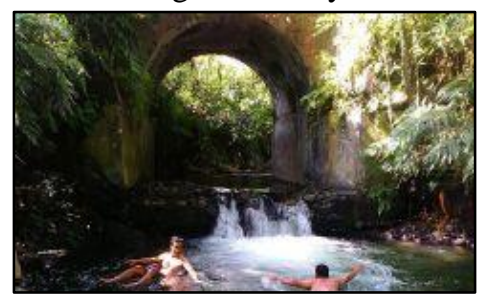

f. Buk londo dan river track

Gambar 1. Kondisi umum Dusun Mendiro.

Permasalahan lain yang dihadapi oleh pengelola desa wisata Dusun Mendiro antara lain: a) belum optimalnya kemampuan sumberdaya dalam manajemen informasi dan tekonologi serta strategi promosi desa wisata, b) pendampingan admnistrasi serta identifikasi profil desa wisata belum tertata dengan baik, dan c) pemetaan spasial potensi, serta basis data dan pengolahan data yang belum terkelola dengan baik.

Berdasarkan analisis permasalahan tersebut, maka perlu dilaksanakan pengabdian masyarakat dengan target Kelompok Swadaya Masyarakat (KSM) Dusun Mendiro yang bertujuan: a) peningkatan sumberdaya media promosi dengan pelatihan Google Form dan media permainan Kahoot yang diukur melalui uji statistik, b) pendampingan administrasi dan identifikasi profil desa wisata, dan c) pendampingan pemetaan spasial.

\section{BAHAN DAN METODE}

\subsection{Objek dan Bahan}

Pengabdian dilaksanakan dengan fokus promosi desa edukasi dan wisata di dusun Mendiro, desa Sukoharjo kecamatan Ngaglik kabupaten Sleman. Peserta pengabdian merupakan pemuda Kelompok Swadaya Masyarakat (KSM) Ngudi Mulyo dusun Mendiro. Pelaksanaan dilaksanakan di Instalasi pengolahan air limbah (IPAL) Komunal Mendiro.

Pengabdian dilakukan secara praktik langsung diantara pemateri dengan peserta kegiatan. Penyuluhan diberikan dengan bantuan media presentasi dan juga didampingi oleh tutor. Hal ini dilakukan supaya materi 
yang diberikan dapat langsung diterapkan dan tidak terlalu banyak teori.

\subsection{Metode}

Metode dalam pengabdian ini dilaksanakan dalam bentuk pembelajaran dan pendampingan masyarakat. Secara detailnya menjadi tiga tahapan, yakni: (1) persiapan, (2) pelaksanaan, (3) evaluasi dan rencana keberlanjutan program.
Tahap persiapan meliputi dua hal utama, yakni: observasi lapangan dan kajian pustaka. Observasi dilakukan guna mengetahui kondisi riil dari tempat pengabdian. Sementara kajian pustaka dilaksanakan dengan mengkaji literatur materi baik yang berkaiatan dengan pendayagunaan maupun optimalisasi promosi dalam pengembangan desa wisata. Tahap pelaksanaan dilaksanakan secara bertahap, supaya tidak jenuh dan menyesuaikan waktu peserta pelatihan. Diagram alir pelaksanaan pengabdian disajikan pada Gambar 2.

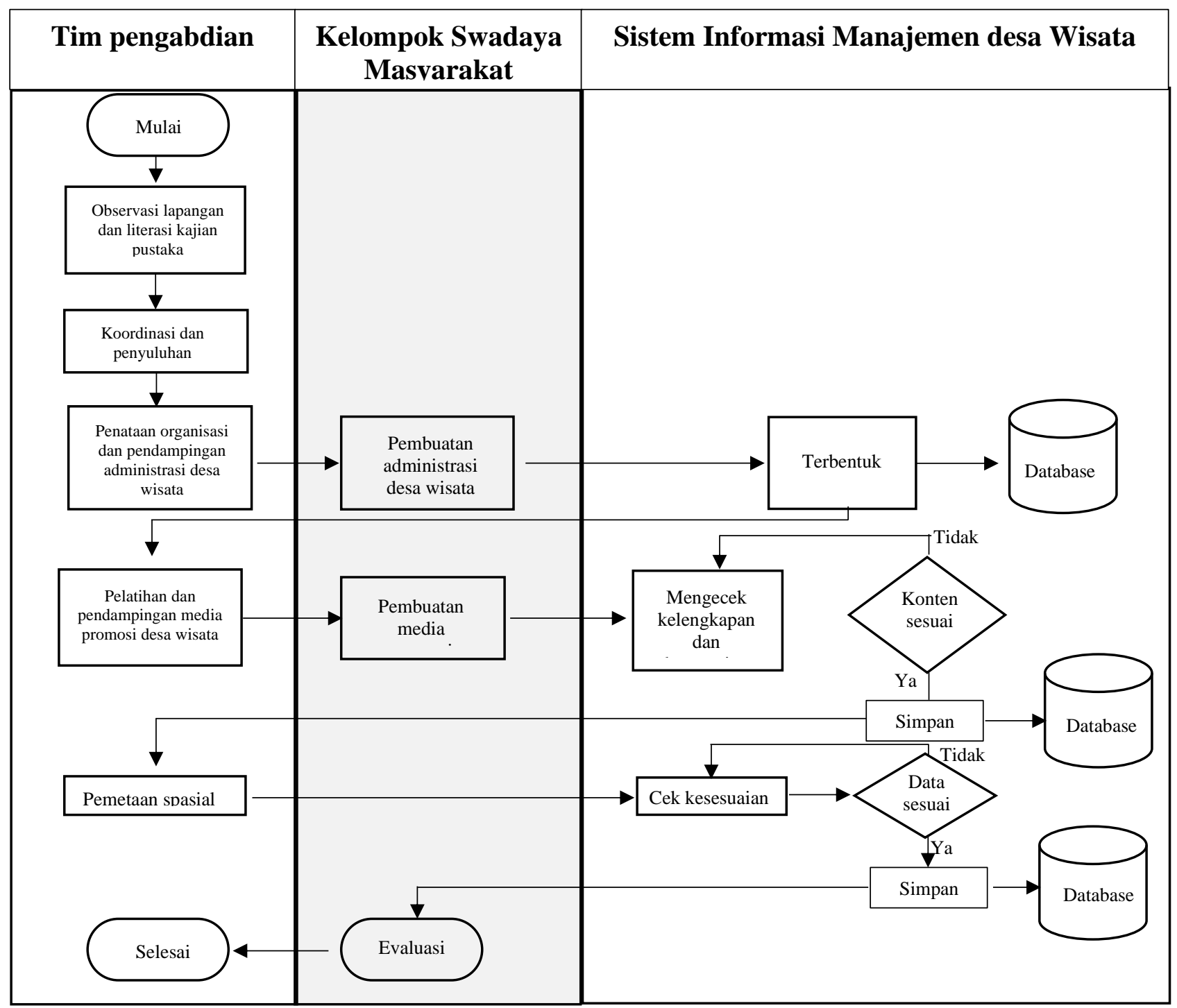

Gambar 2. Diagram alir pelaksanaan pengabdian.

Tahap evaluasi dilakukan dengan cara melihat dampak pelatihan dari sisi kepuasan dan kemampuan peserta. Digunakan statistika deskriptif untuk melihat gambaran umum pelaksanaan, dan uji beda berpasangan untuk melihat apakah terdapat perbedaan rata-rata setelah dilaksanakan pengabdian dibandingkan sebelum dilaksanakan pengabdian. Uji beda berpasangan yang digunakan menggunakan uji paired t-test dengan rumus dituliskan Persamaan 1 (Shier, 2004).

$$
t=\frac{m}{s / \sqrt{n}}
$$

Keterangan:

$m \quad$ :perbedaan rata-rata

$n \quad$ :ukuran sample

s :standar deviasi dari d (d adalah selisih diantara masing-masing pasangan).

Adapun asumsi uji paired t-test meliputi : kedua sampel harus berpasangan, homogen dan selisih nilai setelah dan sebelum berdistribusi normal. Jika asumsi kenormalan tidak terpenuhi, maka digunakan uji non parametrik. Uji non parametrik untuk data berpasangan, 
dapat digunakan paired two-samples Wilcoxon test. Perhitungan paired two-samples Wilcoxon test dituliskan pada Persamaan 2 (Fauzy, 2011).

$$
\begin{gathered}
z_{\text {hitung }}=\frac{W-\mu_{T}}{\sigma_{T}} \\
\mu_{T}=\frac{n(n+1)}{4} \\
\sigma_{T}=\sqrt{\frac{n(n+1)(2 n+1)}{24}}
\end{gathered}
$$

Keterangan

$W_{R} \quad$ : nilai hitung dari uji Wilcoxon, ada 3 kemungkinan, yaitu $W^{+}, W^{-}$, dan $W$. Pemilihan nilai $W$ mana yang akan dipilih berdasarkan kepada uji hipotesis yang akan digunakan.

$n$ : ukuran sampel

\section{HASIL DAN PEMBAHASAN}

\subsection{Gambaran Umum Pelaksanaan Pengabdian}

Pelaksanaan pengabdian masyarakat dilaksanakan dalam kurun waktu 10 bulan, dengan rincian kegiatan sebagai berikut.

a. Koordinasi awal pengabdian masyarakat dengan ketua Kelompok Swadaya Masyarakat (KSM) Dusun Mendiro,

b. Pengambilan data awal pengabdian masyarakat,

c. Penyuluhan awal secara umum,

d. Penyuluhan Google Form sebagai alat bantu perapian administrasi.

e. Penyuluhan media permainan Kahoot sebagai alat bantu evaluasi pengetahuan pengunjung desa wisata

f. Penyuluhan publikasi di media sosial sebagai media promosi desa wisata

Pembinaan dilakukan selama kurun waktu 6 bulan. Pembinaan dilaksanakan pada waktu malam hari karena sebagian besar pemuda bekerja di siang hari. Teknis pembinaan biasanya disepakati terlebih dahulu untuk mengoptimalkan pelaksanaan. Karena sebagian besar pembinaan menggunakan media online, maka dari tim pengabdian memfasilitasi adanya laptop untuk praktik pembinaan dan didampingi oleh rekan mahasiswa Prodi Statistika Universitas Islam Indonesia.

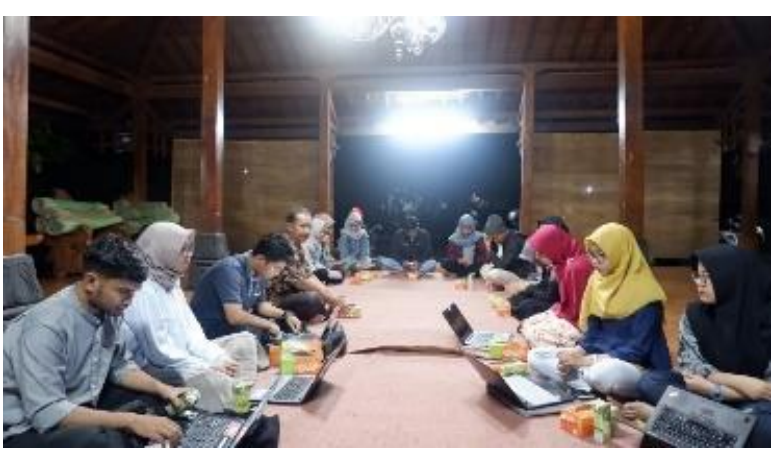

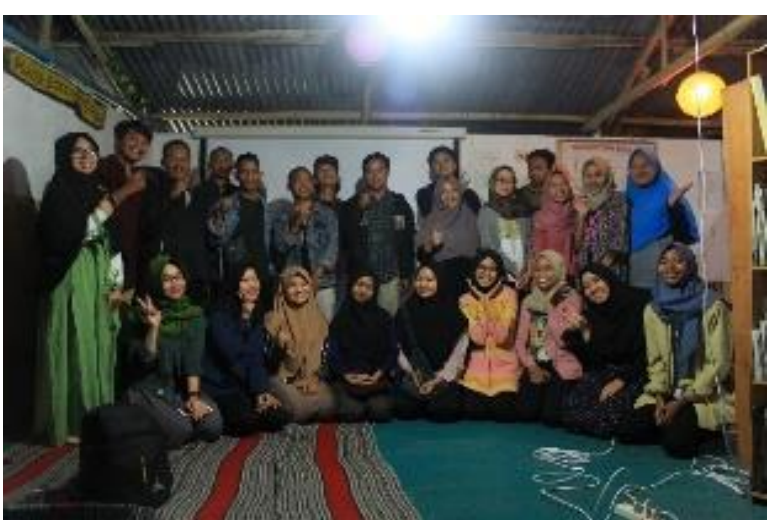

Gambar 3. Dokumentasi pengabdian.

Sebaran usia peserta pelatihan dalam pengabdian masyarakat desa wisata Dusun Mendiro ditunjukan pada Gambar 4. Berdasarkan Gambar 4 diketahui bahwa sebagian besar peserta merupakan masyarakat usia produktif (18-23 tahun).

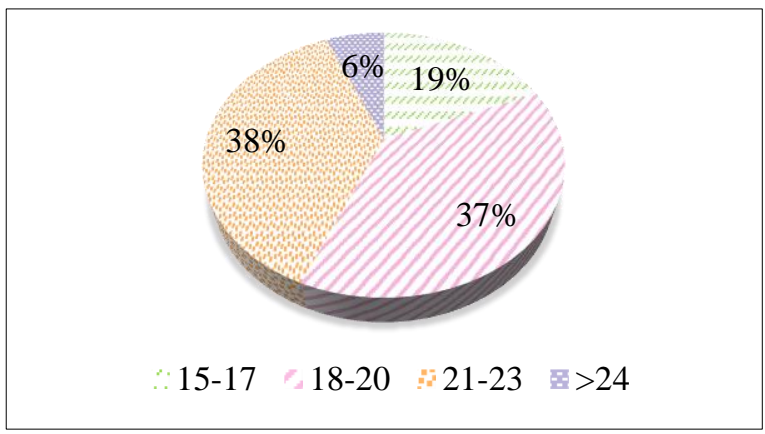

Gambar 4. Sebaran usia peserta pelatihan.

\subsection{Hasil Evaluasi Penyuluhan Google Form dan Media Permainan Kahoot}

\subsubsection{Hasil Evaluasi Penyuluhan Google Form}

a. Statistik Deskriptif

Secara sekilas, hasil pretest dan posttest disajikan pada Tabel 1.

Tabel 1. Statistik deskriptif penyuluhan Google Form

\begin{tabular}{lccc}
\hline Kelompok & $\begin{array}{c}\text { Banyaknya } \\
\text { Peserta }\end{array}$ & $\begin{array}{c}\text { Rata- } \\
\text { rata }\end{array}$ & $\begin{array}{c}\text { Standar } \\
\text { Deviasi }\end{array}$ \\
\hline Pretest & 11 & 74.5 & 12.1 \\
\hline Postest & 11 & 90.9 & 12.2 \\
\hline
\end{tabular}

Berdasarkan Tabel 1 dapat dilihat bahwa rata-rata nilai posttest lebih besar dibandingkan dari pretest, sehingga praduga awal terdapat perbaikan positif setelah dilaksanakan penyuluhan.

b. Visualisasi Data dan Plot Paired Data

Berikut adalah visualisasi dari sebaran kedua nilai serta visualisasi dari nilai berpasangan yang telah dilakukan, disajikan pada Gambar 5 dan Gambar 6. 


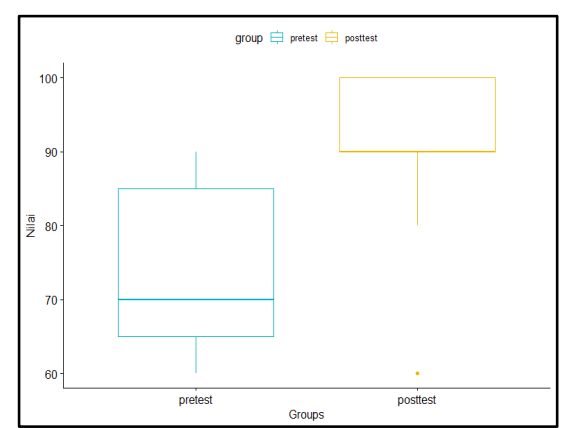

Gambar 5. Visualisasi sebaran data penyuluhan Google Form.

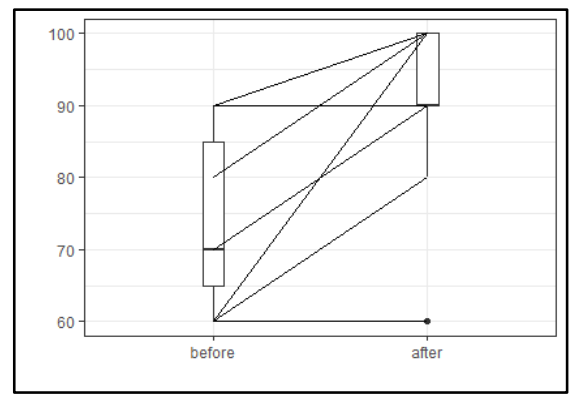

Gambar 6 . Plot paired data penyuluhan Google Form.

\section{Asumsi Paired t-test}

a) Apakah kedua sampel berpasangan?

Iya, karena data yang digunakan berasal dari pengukuran dua kali yang dilakukan terhadap objek yang sama

b) Apakah sample berukuran besar?

Tidak, karena $\mathrm{n}<30$. Perlu dibuktikan apakah distribusi dari difference (selisih) dari posttest dengan pretest berbeda signifikan dari distribusi normal, atau tidak.

c) Kehomogenan variansi

Digunakan untuk mengecek kehomogenan variansi data. Digunakan F-test.

Secara umum, aplikasi dari $F-$ Test digunakan untuk:

- Dalam two samples t-test, diperlukan pemeriksaan "equality" / persamaan variansi dari dua sampel.

- Digunakan untuk membandingkan keragaman (variability) pada pengukuran metode baru dengan metode yang lama. Apakah metode yang baru dapat mengurangi variability dari ukuran yang digunakan.

Hipotesis

$H_{0}$ : variansi dari kedua grup tersebut adalah sama.

$H_{1}$ : variansi dari kedua grup tersebut adalah tidak sama.

$F$ - test statistic diperoleh dengan menghitung rasio dari dua variansi Var (A)/ Var (B). Semakin besar penyimpangan nilai rasio dari 1, maka semakin besar juga bahwa variansi kedua populasi berbeda.

Diperoleh nilai rasio dari variansi sebesar 1.012346 sementara nilai $P-$ value $=0.9849$. Dikarenakan nilai penyimpangan rasio tidak berbeda jauh dari 1 dan nilai $P-v a l=0.9849>0.05=\alpha$ maka gagal tolak $H_{0}$ atau variansi kedua grup tersebut sama.

d) Cek Kenormalan

Digunakan uji Shapiro-Wilk untuk menguji apakah distribusi dari selisih nilai setelah dengan sebelum signifikan berbeda atau tidak dari distribusi normal. Hipotesis

$H_{0}$ : data berdistribusi normal.

$H_{1}$ : data tidak berdisribusi normal.

Diperoleh nilai $\quad p-v a l=0.0475<0.05=\alpha$. Berdasarkan hal tersebut, tolak $H_{0}$ sehingga data tidak berdistribusi normal. Karena data tidak berdistribusi normal, maka digunakan uji non parametrik (paired two-samples Wilcoxon test).

\section{c. Paired two-samples Wilcoxon test}

Paired two-samples Wilcoxon test digunakan untuk mengetahui apakah terdapat perubahan yang signifikan dari nilai sebelum dan sesudah pelaksanaan pelatihan Google Form.

Hipotesis

$H_{0}$ : nilai median dari sampel sebelum dan sesudah penyuluhan tidak berbeda secara signifikan.

$H_{1}$ : nilai median dari sampel sebelum dan sesudah penyuluhan berbeda secara signifikan.

Diperoleh nilai $p$-value $=0.00708<0.05=\alpha$. Berdasarkan hal tersebut maka $H_{0}$ ditolak atau dapat dikatakan nilai median dari sampel dan sesudah penyuluhan berbeda secara signifikan. Kemudian dianalisis lebih lanjut diperoleh nilai median setelah pelatihan lebih besar dibandingkan sebelum pelatihan dikuatkan juga dari deskriptif statistik. Jika berdasarkan nilai peningkatan sebesar $22.01 \%$ dari sebelum dilaksanakan pelatihan. Hal ini dikarenakan pada dari dasarnya pemuda sudah cukup memahami terkait Google Form sehingga dapat kedepannya pemuda KSM Ngudi Mulyo sudah tidak canggung atau sudah siap untuk digunakan ke para pengunjung.

\subsubsection{Hasil Evaluasi Penyuluhan Media Permainan Kahoot}

Langkah-langkah yang dilakukan dalam evaluasi media permainan Kahoot secara umum sama dengan evaluasi pada Google Form. Hasil dari evaluasi penyuluhan Kahoot adalah sebagai berikut.

a. Statistik Deskriptif.

Tabel 2. Statistik deskriptif penyuluhan media permainan Kahoot.

\begin{tabular}{lccc}
\hline Kelompok & $\begin{array}{c}\text { Banyaknya } \\
\text { Peserta }\end{array}$ & $\begin{array}{c}\text { Rata- } \\
\text { rata }\end{array}$ & $\begin{array}{c}\text { Standar } \\
\text { Deviasi }\end{array}$ \\
\hline Pretest & 11 & 57.3 & 20 \\
\hline Postest & 11 & 90.9 & 9.44 \\
\hline
\end{tabular}

Berdasarkan Tabel 2 dapat dilihat bahwa rata-rata nilai posttest lebih besar dibandingkan dari pretest, sehingga praduga awal terdapat perbaikan positif setelah dilaksanakan penyuluhan. 
b. Visualisasi Data dan Plot Paired Data

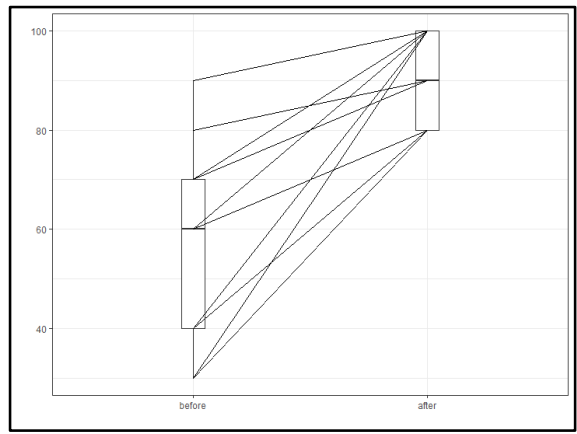

Gambar 7. Visualisasi sebaran data penyuluhan media permainan Kahoot.

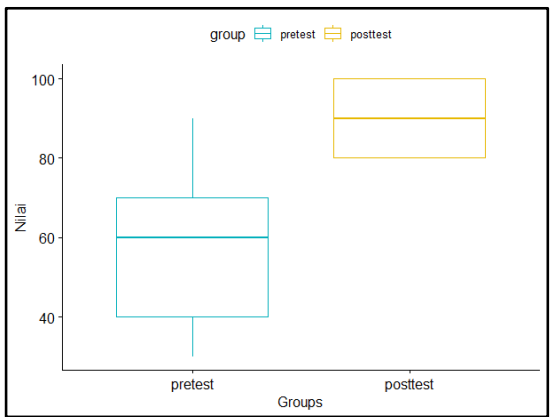

Gambar 8. Plot paired data data penyuluhan media permainan Kahoot.

\section{Asumsi Paired t-test}

Asumsi dari paired t-test terpenuhi dengan penjelasan yang sama seperti evaluasi penyuluhan Google Form. Kemudian dilanjutkan dengan uji kenormalan dari distribusi data. Diperoleh nilai dari $p-$ value $=$ $0.35>0.05=\alpha$. berdasarkan hal tersebut, maka $H_{0}$ gagal ditolak, distribusi dari selisih posttest dan pretest tidak berbeda signifikan dari distribusi normal. Dengan kata lain, kita dapat mengasumsikan berdistribusi normal. Sehingga digunakan uji parametrik (paired sample t-test).

\section{c. Paired samples t-test}

Berdasarkan Persamaan 1, diperoleh diperoleh nilai dari $\left|t_{\text {hitung }}\right|=5.5403>2.228=t_{\text {tabel }}$ maka tolak $H_{0}$ atau rata-rata kedua kelompok adalah berbeda. Hal ini dikuatkan juga dari nilai $p$-value $=0.0002474<$ $0.05=\alpha$. Rata-rata perbedaan (sample estimates) dari kedua kelompok sebesar 33.63 (terjadi peningkatan 58.7 $\%$ setelah diadakan penyuluhan).

\subsection{Hasil Pendapingan Administrasi dan Identifikasi Profil Desa Wisata}

Pendampingan administrasi dilakukan dengan tujuan untuk merapikan pengarsipan data pengunjung yang akan datang. Teknis pendampingan administrasi dilaksanakan bersamaan dengan penyuluhan google form yang sudah dijelaskan sebelumnya. Disamping itu, pendampingan juga dilakukan pada waktu pertemuan rutin pengurus maupun secara informal melalui personal pengurus KSM Ngudi Mulyo.
Selain pendampingan administrasi, tim pengabdian juga melakukan publikasi secara online maupun offline dalam pelaksanaan pengabdian sebagai salah satu upaya menjaga popularitas desa wisata Mendiro. Sebagai ilustrasi disajikan pada Gambar 9.
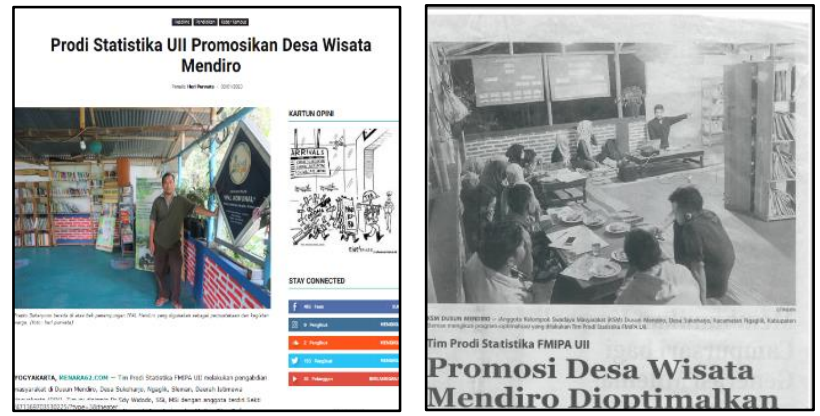

Gambar 9. Contoh publikasi.

\subsection{Hasil Pelaksanaan Pemetaan Spasial}

Pemetaan spasial digunakan untuk memudahkan pengunjung dalam melihat profil desa wisata Mendiro. Hal ini dikarenakan hasil dari pemetaan spasial dapat ditautkan pada link website desa wisata Mendiro. Pelaksanaan pemetaan spasial dilakukan pada waktu sore hari dalam rangka untuk mendapatkan visualisasi yang lebih jelas.

Dalam pemetaan spasial pembinaan menggunakan aplikasi Open Camera dan GPS Essentials. Open Camera digunakan untuk mendapatkan dokumentatsi yang memuat koordinat sehingga memudahkan pembuatan peta tematik. Sementara GPS Essentials digunakan untuk menadai lokasi maupun jalan yang dilalui. Sebagai ilustrasi contoh yang ditargetkan dalam pemetaan spasial pengabdian ini disajikan pada Gambar 10.

Kendati berbagai kendala, pemetaan spasial baru sampai tahapan pengambilan data. Tahapan manutkan hasil pemetaan pada website, dimungkinkan dapat dilaksanakan dalam pembinaan lanjutan.

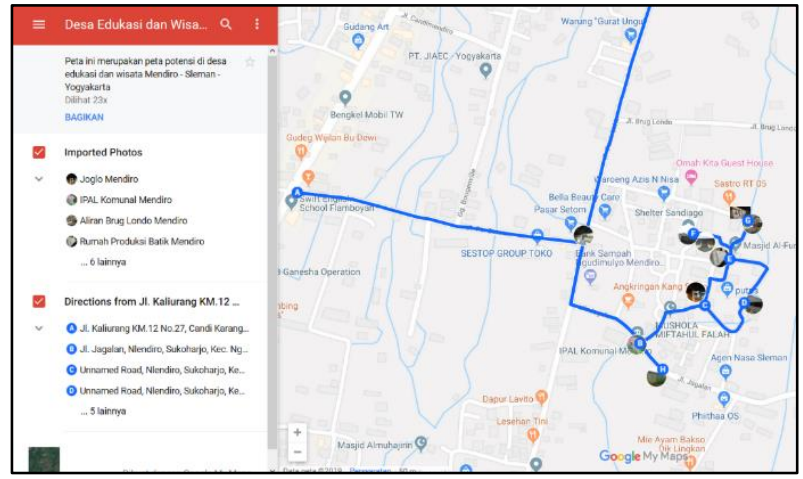

Gambar 10. Contoh dari pemetaan spasial.

\subsection{Evaluasi Pelaksanaan Pengabdian secara Keseluruhan}

Berdasarkan hasil evaluasi diketahui bahwa secara keseluruhan peserta menyadari bahwa keberadaan desa wisata Dsusu Mendiro penting. Hal ini dikarenakan desa 
wisata merupakan upaya pelesatarian kearifan lokal. Selain itu, dengan adanya desa wisata dapat meningkatkan perekonomian warga desa. Secara keseluruhan peserta menyatakan bahwa adanya pelatihan yang diberikan oleh tim bermanfaat dan perlu diadakan kembali. Materi penyuluhan yang disampaikan dapat digunakan oleh peserta untuk mengelola desa wisata. Pengelolaan yang dimaksud yakni dalam hal promosi desa wisata, administrasi, pendokumentasian kegiatan, dan lain-lain.

Peserta menilai bahwa materi pelatihan yang diberikan mudah dimengerti dan pemateri sangat memahami materi yang disampaikan. Dalam pelatihan, pemateri berusaha untuk menyampaikan materi dengan bahasa yang mudah dipahami dengan peserta yang mayoritas anak muda. Selain itu, peserta pelatihan memperoleh praktik langsung dalam materi yang diberikan sehingga dapat memahami materi dengan baik.

Para peserta menilai bahwa pemateri mampu memberikan jawaban atas pertanyaan peserta dengan baik dan dapat meningkatkan pemahaman peserta. Pada sesi diskusi dan tanya jawab, peserta diberikan keleluasan untuk mengulas kembali dan menanyakan materi pelatihan kepada pemateri. Hal ini dimaksudkan agar materi dapat lebih dipahami oleh peserta. Sementara itu, aspek lain penilaian peserta terhadap pelatihan yang dilaksanakan disajikan Gambar 11 hingga Gambar 15.

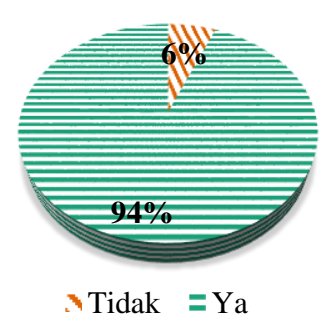

Gambar 11. Kepentingan pelatihan bagi peserta.

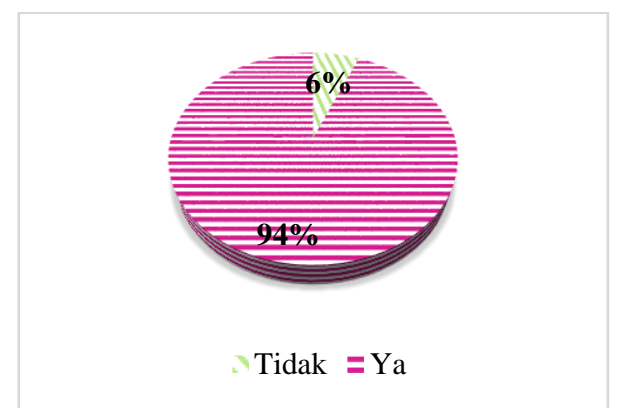

Gambar 12. Penilaian peserta terhadap materi yang terorganisasi dengan baik.

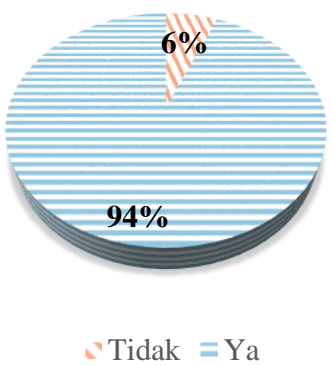

Gambar 13. Penilaian peserta terhadap kesesuaian materi yang disampaikan.

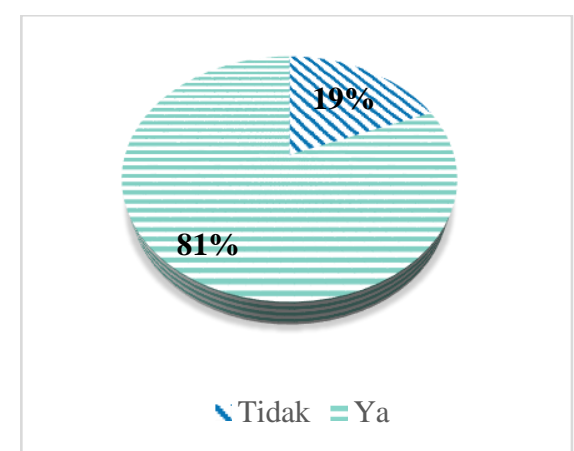

Gambar 14. Penilaian peserta terhadap kecukupan alokasi waktu penyampaian materi.

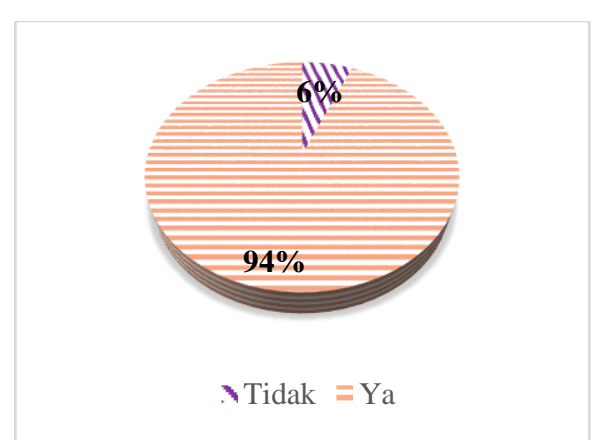

Gambar 15. Penilaian peserta terhadap kecukupan alokasi waktu dalam diskusi.

\section{KESIMPULAN}

Berdasarkan latar belakang dan tujuan dari pengabdian ini, diperoleh simpulan sebagai berikut.

1. Secara keseluruhan, optimalisasi media promosi desa wisata secara online maupun offline berjalan sesuai dengan rencana dalam kurun waktu 11 (sebelas) bulan dari April 2019 - Januari 2020 dengan objek utama dari pelaksanaan pengabdian adalah pemuda KSM Ngudi Mulyo dusun Mendiro Desa Sukoharjo Kecamatan Ngaglik Kabupaten Sleman.

2. Setelah dilaksanakan pendampingan, terjadi peningkatan dari kualitas SDM khsusnya dari administrasi dan identifikasi profil desa wisata dusun Mendiro. Selain itu, diperoleh juga peningkatan dalam hal kemampuan pembuatan media kusioner untuk pengunjung menggunakan Google Form dan media permainan menggunakan Kahoot yang ditunjukan dari nilai pretest dan posttest dengan uji parametrik dan non parametrik. 
3. Kaderisasi pengembangan basis usaha dapat dilanjutkan dengan pengurus KSM Ngudi Mulyo yang sudah diberikan penyuluhan terkait promosi secara online dan offline.

\section{UCAPAN TERIMA KASIH}

Tim pelaksana mengucapkan terima kasih atas dukungan penuh kepada Direktorat Penelitian dan Pengabdian Masyarakat Universitas Islam Indonesia (DPPM UII) melalui dana Hibah Pengabdian Unggulan Tahun 2019. Tim pelaksana juga mengucapkan terima kasih kepada pemuda Kelompok Swadaya Masyarakat (KSM) Dusun Mendiro Kelurahan Sukoharjo Kecamatan Ngaglik Kabupaten Sleman Yogyakarta sebagai rekan kerjasama dalam pelaksanaan Pengabdian Masyarakat.

\section{DAFTAR PUSTAKA}

Fauzy, A. (2011). Statistik Nonparametrik. Yogyakarta: Ardana Media. Diambil kembali dari NCSSStatistical Software: https://ncsswpengine.netdna-ssl.com/wpcontent/themes/ncss/pdf/Procedures/PASS/Paire d_Wilcoxon_Signed-Rank_Tests.pdf

Gunn, C. (2002). Tourism Planning. New York: Taylor and Francis.

Puta, H. S. (2018, Maret 26). Pengembangan Desa Wisata untuk Kesejahteraan Masyarakat. Diambil kembali dari Universitas Gadjah Mada: https://ugm.ac.id/id/berita/15939-

pengembangan.desa.wisata.untuk.kesejahteraan. masyarakat

Shier, R. (2004). Paired t-tests. Diambil kembali dari Mathematics Learning Support Centre: http://www.statstutor.ac.uk/resources/uploaded/ paired-t-test.pdf

Yoeti, O. (1996). Pengantar Ilmu Pariwisata. Bandung: Angkasa Bandung. 